Research Article

\title{
Dimensional, Mechanical and LCA Characterization of Terrazzo Tiles along with Glass and Construction and Demolition Waste (CDW)
}

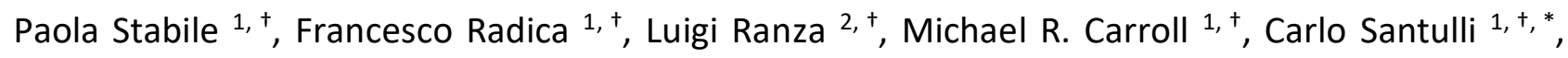 \\ Eleonora Paris ${ }^{1,+}$
}

1. School of Science and Technology, Geology Division, University of Camerino, Via Gentile III da Varano, 62032 Camerino, Italy; E-Mails: paola.stabile@unicam.it; francesco.radica@unicam.it; michael.carroll@unicam.it; carlo.santulli@unicam.it; eleonora.paris@unicam.it

2. CIAOTECH S.r.I. (PNO Innovation BV), Via Palestrina 25, 00189 Roma, Italy; E-Mail: l.ranza@ciaotech.com

† These authors contributed equally to this work.

* Correspondence: Carlo Santulli; E-Mail: carlo.santulli@unicam.it

Academic Editor: Luciano Ombres

Special Issue: Fiber Composite Materials and Civil Engineering Applications

Recent Progress in Materials

2021, volume 3, issue 1

doi:10.21926/rpm.2101006
Received: December 12, 2020

Accepted: February 20, 2021

Published: March 02, 2021

\begin{abstract}
In this work, two types of wastes were introduced, namely, glass from municipal waste and Construction and Demolition Waste (CDW). The latter, which was obtained from rubble generated by the seismic events occurred in Central Italy in 2016, was introduced in two configurations, the single-layer and the double-layer of the cement-based Terrazzo tiles. A maximum of $77 \%$ of waste introduction was proven to be possible, therefore creating the possibility of obtaining construction products including high quantities of secondary raw materials, coupled with a valuable aesthetic aspect. The tiles represent a novel CDW upcycling application and follow the EU recommendations to improve the circular economy in the building sector. In particular, the products obtained showed dimensional conformity in the specifications and mechanical performance in the case of double-layer tiles as
\end{abstract}

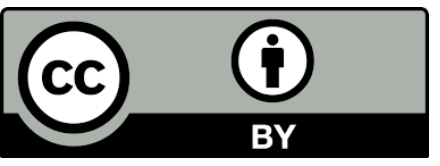

(C) 2021 by the author. This is an open access article distributed under the conditions of the Creative Commons by Attribution License, which permits unrestricted use, distribution, and reproduction in any medium or format, provided the original work is correctly cited. 
required by the envisaged use in the flooring (EN 13748-1). A life cycle analysis (LCA) clarified the possible advantages in terms of reduced resource depletion (RD) and global warming potential (GWP). The evaluation at the aggregate/glass matrix interface indicated good performance of the tiles, demonstrating the readiness for industrial production and market introduction.

\section{Keywords}

Construction and demolition waste (CDW); terrazzo tiles; mechanical properties; life cycle assessment

\section{Introduction}

The European Union (EU) has identified the Construction and Demolition Waste (CDW) as a priority waste stream due to the huge amounts generated, which is approximately 800 million metric tons, corresponding to $30 \%$ of the total waste generated [1-2]. For this reason, the EU has set for its member states an ambitious target regarding the recycling of the CDW. According to the Waste Framework Directive (WFD) 2008/98/EC, the minimum recycling amount for non-hazardous CDW needs to be at least 70\% in weight by 2020 [3-4]. More specific to the construction industry, the Sustainable Construction Strategy (2008) also sets overall targets for reducing the landfilling of the CDW [5]. The construction industry sector generates about $35 \%$ of waste in landfills all across the globe [6]. As a consequence, the need for the construction sector to promote actions to reduce greenhouse gas (GHG) emissions, mitigate climate change and resource depletion are recognized worldwide. In this framework, a circular economic approach that focuses on concepts of reusing and recycling could ensure more sustainable use of construction materials [7-9].

Currently, the CDW recovery varies widely across the member states of the EU; for instance, Austria and Germany have already reached the 2020 target, and other countries, such as Finland, are just behind with a CDW material recovery rate of ca. $58 \%$ [10]. This variability mainly occurs due to a lack of uniform standards among different EU countries, the risk avoidance concerns (e.g., asbestos), the lack of experience, and the lack of mature and effective technologies used to separate and reuse waste fractions (e.g., ceramics, bricks, gypsum, stones, etc.), which might favor the recycling of the CDW back in the manufacturing loops. Also, the composition of the CDW strongly changes between the other member states and the geographical areas. Even in the same country, the CDW usually appears in a complex and mixed form, making it very difficult to separate and recycle. It is strictly related to the type and age of buildings, the construction styles, and the geological availability of different types of rocks.

A matter of interest in the construction industry is the possible recycling of waste into new building materials. Often, the main option for recycling this type of waste is still by downgrading the applications into aggregates for road construction, embankment, or backfilling [11-12]. Also, with limitations in mechanical performance, the aggregates are recycled into concrete [13]. However, this issue has drawn much more attention in recent years, as well as recycling the glass waste of asphalt shingle for use as a raw material in the manufacturing of cement [14-17]. 
The use of recycled aggregates (RA) from the CDW in concrete mixes has been widely explored to improve the up-cycling [18-21]. Concrete is the most widely used construction material, and its production is dependent on primary raw materials such as cement, sand, gravel, and water [19]. Although this results in a huge production of concrete, there is a high level of consumption of natural resources. For this reason, recycled aggregate, which originates from the CDW, can partially or fully replace natural aggregates in the concrete mixture, representing one of the most effective approaches in utilizing the CDW. To be suitable for RA use, the CDW needs to be treated first and be free of undesired and more lightweight fractions (e.g., plastic, wood, ferrous metals, rubber, and gypsum) [20]. Apart from the use of the CDW in the RA that could result to be technically performant, there are also various studies focused on the use of the lighter fraction for the preparation of recycled insulation materials [22-25].

Another important issue concerning municipalities worldwide is the recycling of waste glass. For instance, the usage of recycled glass as a new and high-quality glass is limited due to the presence of impurities or mixed colors [14]. Recently, studies have also been devoted to the use of waste glass as aggregates for cement concrete or as replacements for cement [26-31]. This substitution can result in a slightly negative effect on the workability, strength, and the freezeresistance of the cement concrete, which could be mitigated by partially replacing the Portland cement with other pozzolanic materials such as the fly ash or metakaolin [14 and references therein].

Due to the low economic costs required for landfilling, lack of incentives, and sometimes due to outdated regulations, the use of virgin aggregates is still preferred over that of the recycled aggregates [32-33] in the building industry. Thus, there is an important need to develop new applications and products that can be more suitable for waste recycling toward the overall circular economy action plan of the EU.

Many EU projects have worked on the management strategies and applications regarding the CDW with a particular aim in developing upcycling technologies to recover aggregates from complex CDW, and to produce pre-fabricated building blocks using high percentages of CDW, or to embed the CDW in a geopolymer matrix for insulating elements (e.g., InnoWEE, RE4, HISER, IRCOW, C2CA) [5]. The EU-Life project 'ECOTILES' (https://www.ecotiles-lifeproject.eu/) provided its contribution toward the reduction and reuse of the CDW. In particular, the project aimed at introducing environmental improvements in the production of the traditional cement-based tiles, by obtaining products containing more than $70 \%$ waste. This result was achieved by including recycled glass and ceramics from urban/industrial wastes and CDW; this reduces the environmental impact of the Terrazzo tile production compared to the traditional Terrazzo tiles while achieving the production of high-grade pre-casted products.

Terrazzo tiles having dimensions of $300 \times 300 \times 30,250 \times 250 \times 25$, and $200 \times 200 \times 20 \mathrm{~mm}$ are widely used, and can be produced in two varieties, single or double layer, with the latter consisting of two layers, the upper exposed to friction conditions, and the lower in contact with the floor mat [34]. Over the years, the Terrazzo tiles proved to be more suitable for the introduction of waste from the building industry, in which they are precast and are not structural elements [35]. Efforts were made in a study on recycling and reuse of waste materials to obtain different constructive elements. For instance, it is possible to produce concrete for pavement blocks using concrete and ceramic recycled aggregates along with mechanical properties similar to those of the natural aggregates, without needing to increase the amount of cement [36]. 
The main objective of the present study is the characterization of the Terrazzo tiles incorporating the glass waste and the CDW. In particular, the introduction of local CDW into the Terrazzo tiles is considered alongside the compliance of the product obtained with the dimensional and mechanical specifications, leading to two types of Terrazzo tiles, referred to as the single layer and the double layer. The sense of bringing this operation to the level of industrialization is also clarified by comparing the traditional products offered and produced by all newly obtained materials.

In particular, concerning the seismic events that occurred in central Italy during 2016, a considerable amount of CDW was produced, estimated to be around 2.667.000 tons [37], which is a number highly underestimated as it accounts only for the damages incurred by public buildings. Therefore, a large amount of CDW produced by earthquakes would be present in the area for many years until reconstructions are carried out. For this reason, a virtuous environmental procedure suggests as much disposal possible for local productions, not far from the stocking sites. This has been realized thanks to the involvement of a local producer in the project that has directly guided all the prospects of industrialization of the project.

Finally, the cost and environmental impact, together with associated savings, is evaluated using the Life Cycle Assessment (LCA) on the product (EN ISO, 2006a, 2006b). The importance of performing the LCA studies has currently increased, probably as a result of the latest European Directives on the construction of buildings (Directive 2010/31/EC, Directive 2008/98/CE). The LCA application is based on a general evaluation of the environmental waste management system; however, many studies are particularly devoted to investigating the Construction and Demolition of the Waste environmental performance [38-40].

In this work, the results of the LCA carried out on both the traditional and "eco" (including waste) versions of the Terrazzo tiles from the same manufacturer are presented to compare their respective environmental impacts. All the measurement and analysis concerning the Terrazzo tiles have been made to assess the environmental benefit of avoiding the accumulation and treatment of waste and to transform it from an environmental problem to a valuable product at an industrial scale, as well as to check the guarantee of these products and if they are permissible for internal use according to the mandatory European Standards.

\section{Materials and Methods}

For better clarity regarding the objectives of the study, the main stages of the experimental work carried out for the production and testing of the Terrazzo tiles are reported in Figure 1 and explained in the following paragraphs. 


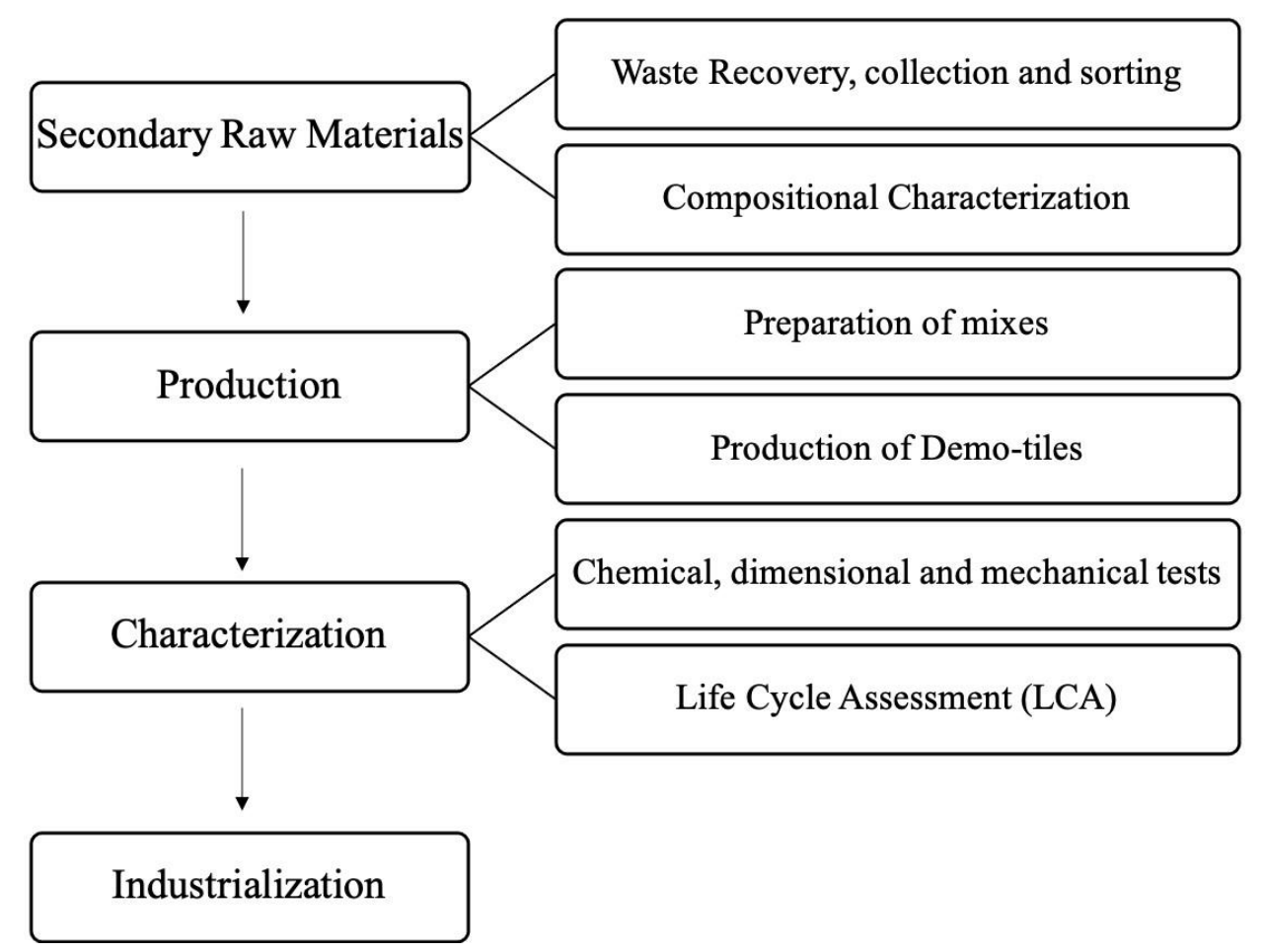

Figure 1 Chart with the main steps of the experimental work.

\subsection{Waste Characterization}

\subsubsection{Construction and Demolition Waste (CDW)}

The CDW sample used in this study was collected from the centralized CDW processing plant (COSMARI in Macerata, Italy) that, after the 2016 seismic crisis that impacted four Regions in Central Italy, is the plant in charge of collecting, separating, and distributing all the earthquake rubble from the entire Marche Region. The high compositional heterogeneity of the CDW required a strict control of the grain size to obtain a suitable product. In particular, the CDW used ceramic, bricks, and other construction materials such as cement and concrete fragments. Due to its composition, it is highly non-homogeneous and unsuitable to be utilized as an aggregate for the Single Layer (SL) tiles for aesthetic reasons. However, it has been inserted and used successfully in powders in the lower layer of the Double Layer (DL) tiles.

CDW mineralogical composition has been analyzed by X-ray powder diffraction method (XRPD) using an automated PHILIPS PW1830 diffractometer equipped with a $\mathrm{Cu}$ Ka X-ray generator $(\lambda=$ $1.5418 \AA$ ). A Cu X-ray tube was operated at $40 \mathrm{kV}$ and $25 \mathrm{~mA}$, and the data were collected in the step scan mode with a Bragg angle $2 \theta$ range from $3^{\circ}$ to $75^{\circ}$, a scanning step of $0.02^{\circ}$ and counting time of $1 \mathrm{~s}$, respectively. The XRPD pattern of the CDW is reported in Figure 2, which shows the presence of Alite (Al), Belite (BI), Celite (Cl), Calcite (Cal), and Quartz (Qz) with traces of Gypsum (Gy), wherein Calcite and Quartz are the predominant phases. 


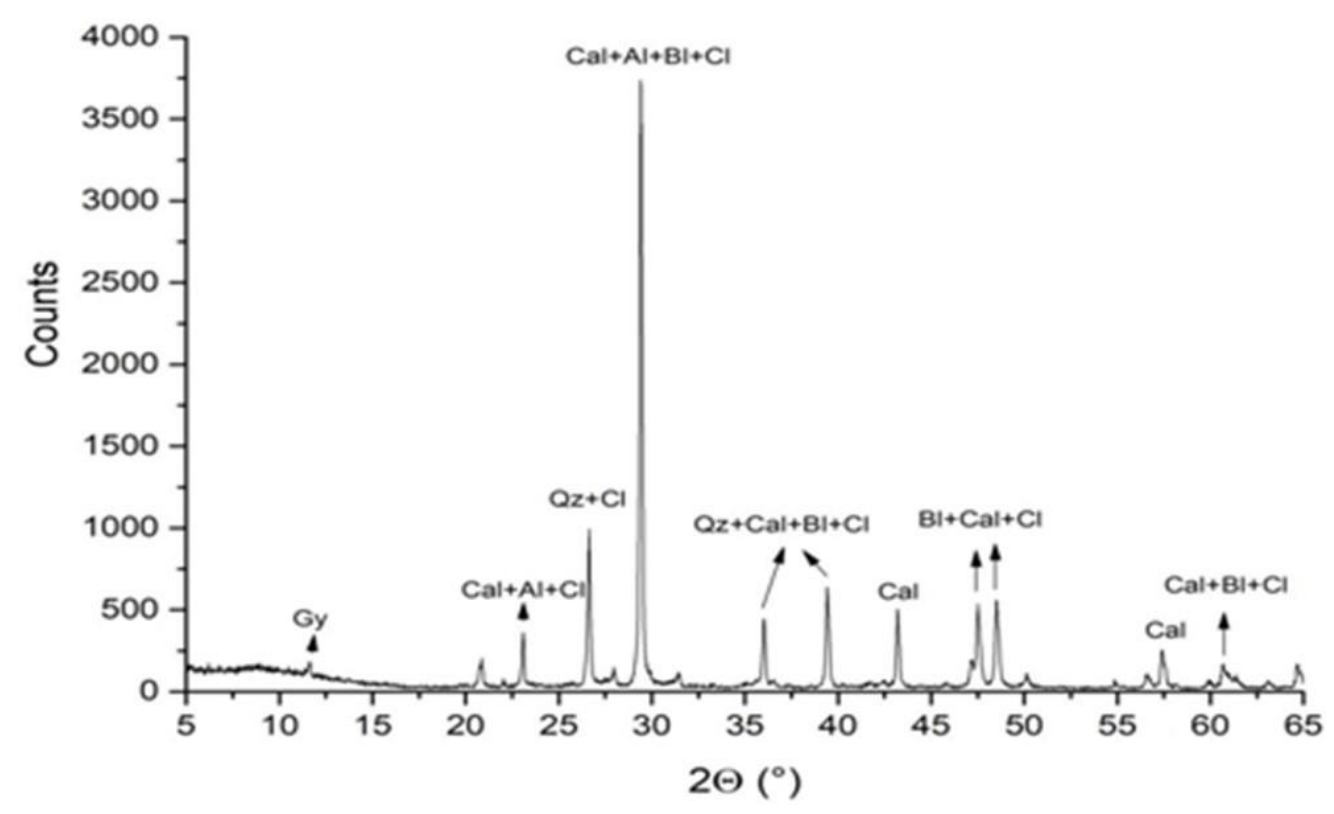

Figure 2 XRPD pattern of Construction and Demolition Waste mineralogical phases. Present phases are Alite (Al), Belite (BI), Celite (Cl), Calcite (Cal), Quartz (Qz), and Gypsum (Gy).

\subsubsection{Glass Waste}

Chemical analyses of the major elements of the green-colored glass waste sample used were obtained by the Electron Micro-Probe (EMP) using a CAMECA SX50 at the Consiglio Nazionale Delle Ricerche (CNR) - Institute of Geosciences and Earth Resources (IGG) in Padova (Italy). The measurements were performed with an acceleration voltage of $20 \mathrm{keV}$, a beam current of $2 \mathrm{nA}$ for $\mathrm{K}, \mathrm{Na}, \mathrm{Al}$, and $\mathrm{Si}$, all measured at first, and a beam current of $20 \mathrm{nA}$ for all the other elements. During the analysis, a slightly defocused (ca. 10 micrometers) beam was used to minimize the alkali volatility. Sample composition is given in wt\% oxides along with variance in Table 1.

Table 1 Chemical oxides composition (wt.\%) of waste glass.

\begin{tabular}{|c|c|c|c|c|c|c|c|c|c|c|c|}
\hline Wt \% & $\mathrm{SiO}_{2}$ & $\mathrm{TiO}_{2}$ & $\mathrm{Al}_{2} \mathrm{O}_{3}$ & $\mathrm{Fe}_{2} \mathrm{O}_{3}$ & MgO & $\mathrm{CaO}$ & $\mathrm{BaO}$ & MnO & $\mathrm{Na}_{2} \mathrm{O}$ & $\mathrm{K}_{2} \mathrm{O}$ & TOTAL \\
\hline GFI-1 & 70.98 & 0.06 & 2.01 & 0.34 & 2.33 & 10.92 & 0.04 & 0.02 & 10.05 & 0.84 & 97.58 \\
\hline GF-1-1 & 70.77 & 0.07 & 2.53 & 0.28 & 2.35 & 10.93 & 0.06 & 0.03 & 10.14 & 1.10 & 98.26 \\
\hline Variance & 0.022 & 0.00005 & 0.1352 & 0.0018 & 0.0002 & 0.00005 & 0.00002 & 0.00005 & 0.0041 & 0.0338 & - \\
\hline
\end{tabular}

It does not total to 100 because of the presence of other minor elements (e.g., S, Pb, Ni, Co), whose presence has also been investigated but resulted in concentrations below the detection limit of the instruments. 


\subsection{Terrazzo Tiles Production}

The production of Terrazzo tiles has been experimented in two common versions, namely the $S L$ and the DL (Figure 3). The SL and the upper layer of the DL tiles, which also represent the decorative part of the tiles, are composed of a mixture of a) waste glass (or marble granulate or aggregate), b) recycled waste glass (quartz or marble powder) which is powdered to less than 100 microns, c) Portland cement, and d) pigments. The bottom layer of the DL is composed of the CDW and Grey Portland cement. This choice of components evidences that the eco-version of the Terrazzo tiles described was mostly made using waste materials, obtaining substantially less environmental impact compared to the "traditional" Terrazzo tiles, which are composed exclusively of marble granulate, cement, and pigments (in $\mathrm{SL}$ ) or quartz sand and cement (in $\mathrm{DL}$ ). The use of glass in the upper layer also allows obtaining a product of aesthetic value, with a modern, appealing, and fresh look, competing with current best-in-market products for use in interiors.

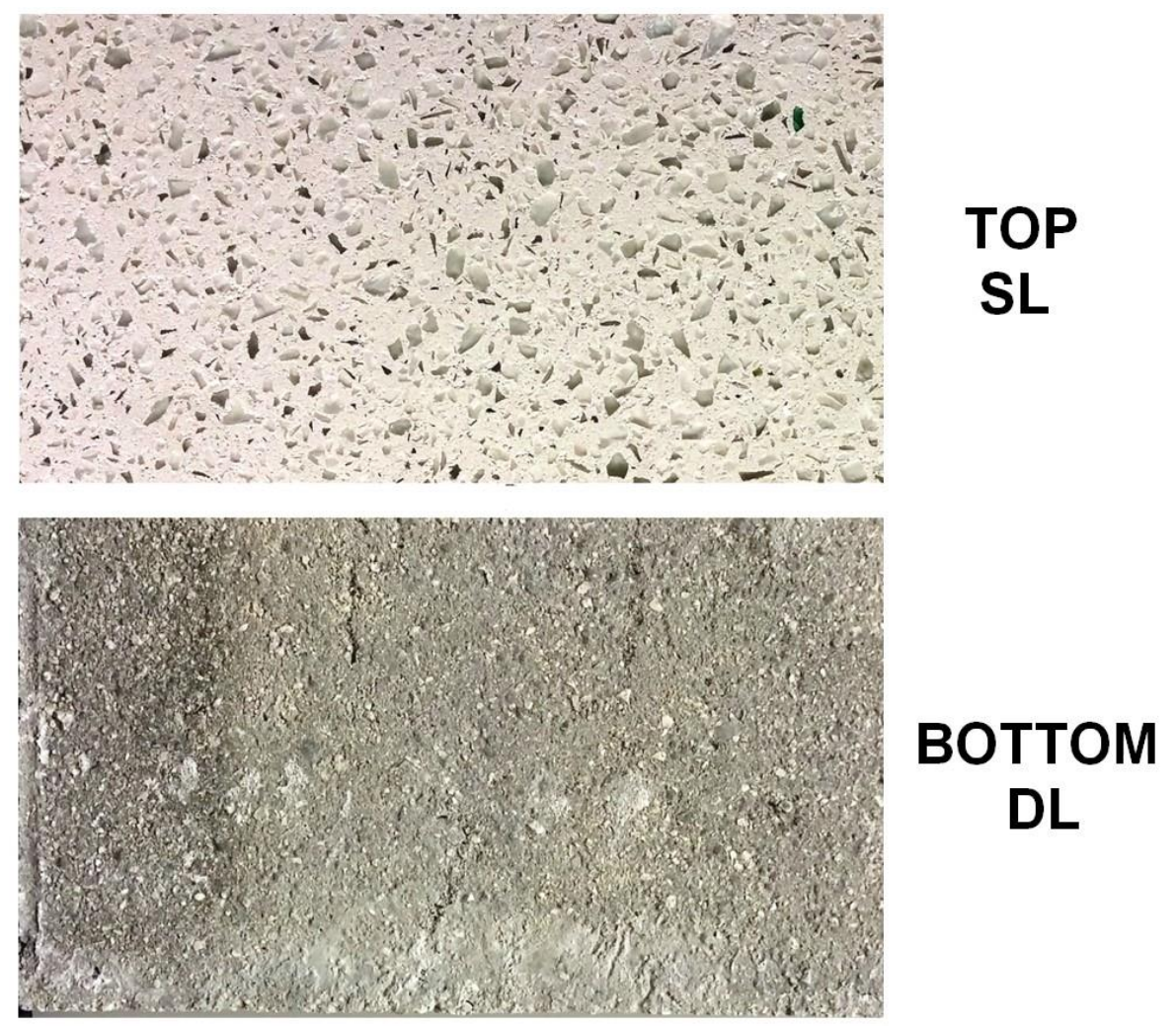

Figure 3 Top view of a single layer $(S L)$ and bottom view of a double layer (DL) ecological (ECO) tile produced with the introduction of glass waste and CDW.

All the dosages of the Terrazzo tile components used in this work are displayed in Table 1. The dosages were calculated according to the original dosages from the producer (Grandinetti, the Italian company also EU-Life project partner, www.grandinetti.it), revised to include waste materials. An equal proportion of natural aggregates was replaced by the secondary raw materials in both the mixes for the $S L$ and $D L$ tiles. Thus, the mixes were obtained as per the following ratios: cement/glass (granulate and powder) $=1 / 3.5$ in the case of SL tiles; cement/CDW $=1 / 3$ in the case of DL tiles. Keeping the water content constant (11.8\%), the cement content was modified in the 
two tile mixes to get the exact water/cement $(\mathrm{w} / \mathrm{c})$ ratio of 0.60 in the $S L$ tile mix and 0.56 in the DL tiles, respectively. The mixing procedure consists of the following steps: 1) Add water in the mixer, 2) Later add cement and mix for a few minutes, 3) finally, add the aggregates and mix once again.

Once prepared, the mixes were poured into the molds and were subjected to vibration and pressing to remove excess water. After all the products were made, they were subjected to curing before being tested. The curing was carried out using a micro-camera system, a closed container that enables the curing of mixtures without the help of additional steaming but by using the heat produced by the exothermic reaction of the cement during its natural hardening cycle. This allows the reduction of curing time from 28 to 20 days and less (Grandinetti company patent).

The final products consist of cement-based tiles with a lateral size of $250 \times 250 \mathrm{~mm}$ and a thickness of $13 \mathrm{~mm}$ for a single-layer and $23 \mathrm{~mm}$ for the double-layer tiles. Thickness values refer to the post-polishing data, which resulted in the reduction of the thickness of 2-3 mm. This production allowed, including up to $77 \%$ of glass in the SL tiles and $75 \%$ of waste materials in the bottom layer of the DL tiles, respectively. In particular, Table 2 shows the comparison between the DL-Ecological (DL-ECO) and DL-Traditional (DL-TRA) tiles in terms of material composition: about $37 \%$ in weight of the TRA-tile bottom layer is composed of sand, which is substituted by the CDW, while about $40 \%$ of the weight of the TRA-tile upper layer is usually composed of marble, that is substituted by the recycled glass in the ECO-tile. This procedure allows the insertion of considerable amounts of waste in the ECO-tiles, avoiding the use of new raw materials and at the same time, maintaining its characteristics and the scope of possible applications as a high-grade product.

Table 2 Main characteristics and composition of each type of tiles.

\begin{tabular}{lllll}
\hline & SL-TRA & SL-ECO & $\begin{array}{l}\text { DL-TRA } \\
\text { (bottom layer) }\end{array}$ & $\begin{array}{l}\text { DL-ECO } \\
\text { (bottom layer) }\end{array}$ \\
\hline Width (mm) & 250 & 250 & 250 & 250 \\
Final thickness (mm) & 13 & 13 & 23 & 23 \\
Final weight (kg/m $\mathbf{m}^{\text {) }}$ & 32.5 & 32.5 & 57.5 & 57.5 \\
Cement (\%) & 22 & 22 & 25 & 25 \\
Marble (\%) & 77 & - & 75 & - \\
Glass (\%) & - & 77 & - & - \\
CDW (\%) & - & - & - & 75 \\
Pigment (\%) & 1 & 1 & - & - \\
\hline
\end{tabular}

\subsection{Tests}

For the industrial production and commercialization of Terrazzo tiles, there is a requirement to determine their correspondence to the standard norm UNI EN 13748-1 "Terrazzo tiles for internal use". The tests are determinant in assuring the feasibility of the types of tiles produced and their acceptance in the market. 


\subsubsection{Dimensional Compliance}

The test verifies if the format of the Terrazzo tiles is consistent with the specifications given by the manufacturer with regards to the length, width, and thickness (Figure 4).

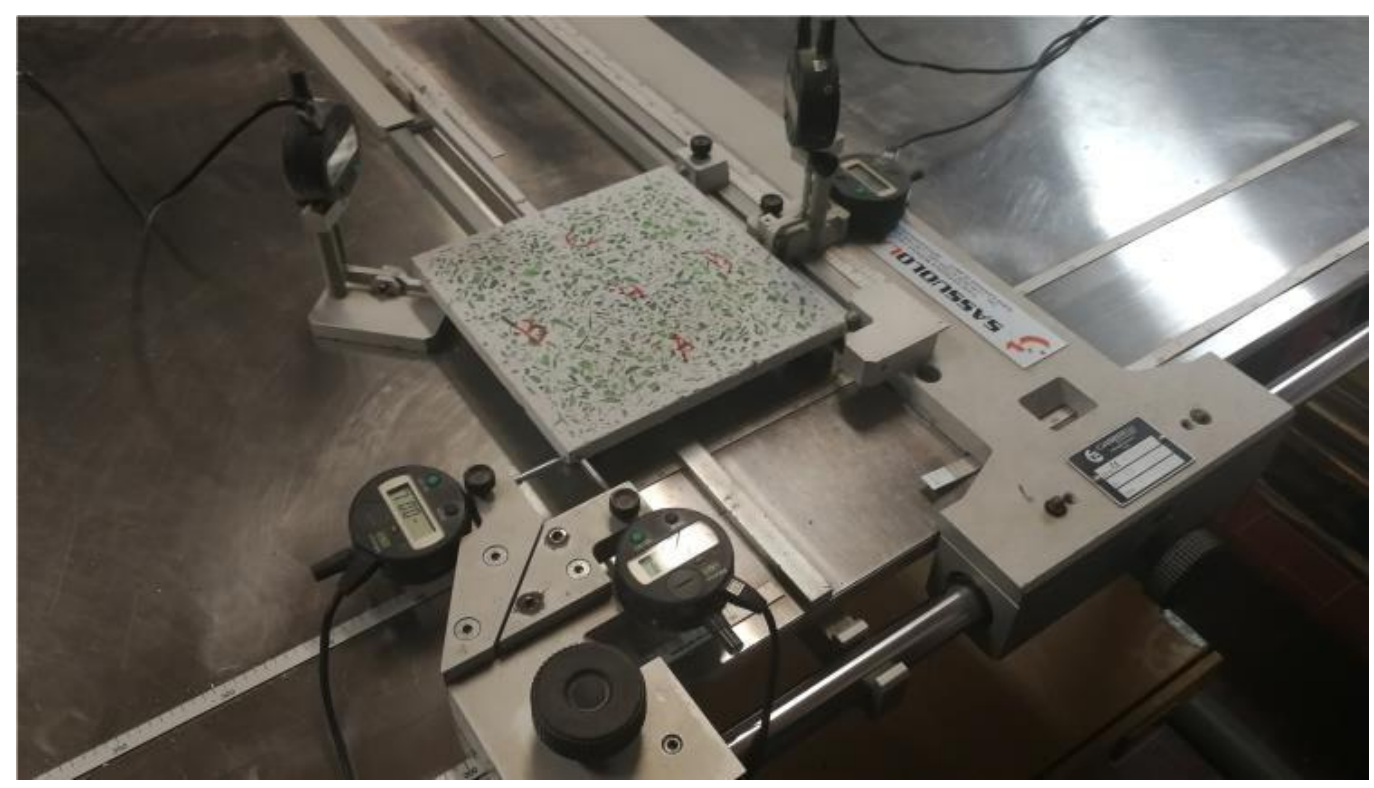

Figure 4 Set-up for dimensional compliance measurements.

- Dimensional deviations (UNI EN 13748-1 5.1): Individual tiles, when tested shall conform to the declared work dimensions of the manufacturer within the permissible deviations. Dimension Tolerance: Length at edges $\pm 0.3 \%$; Thickness of the tile $\pm 2 \mathrm{~mm}$ (for a thickness $<40 \mathrm{~mm}$ ), $\pm 3 \mathrm{~mm}$ (for a thickness $\geq 40 \mathrm{~mm}$ ).

- Straightness of edges of the upper face (UNI EN 13748-1 5.2): the maximum discrepancy between the nominal and measured value of the edge shall not exceed $\pm 0.3 \%$ of the length of the considered edge.

- The flatness of the upper face (UNI EN 13748-1 5.4): no point shall deviate from the surface by more than $0.3 \%$ of the length of the considered diagonal. This does not apply to the textured upper faces.

\subsubsection{Mechanical Testing}

Breaking strength and load tests are performed in a transverse testing machine (Figure 5). It is constructed in such a way that it can induce the three-point bending into the sample without torsion. 


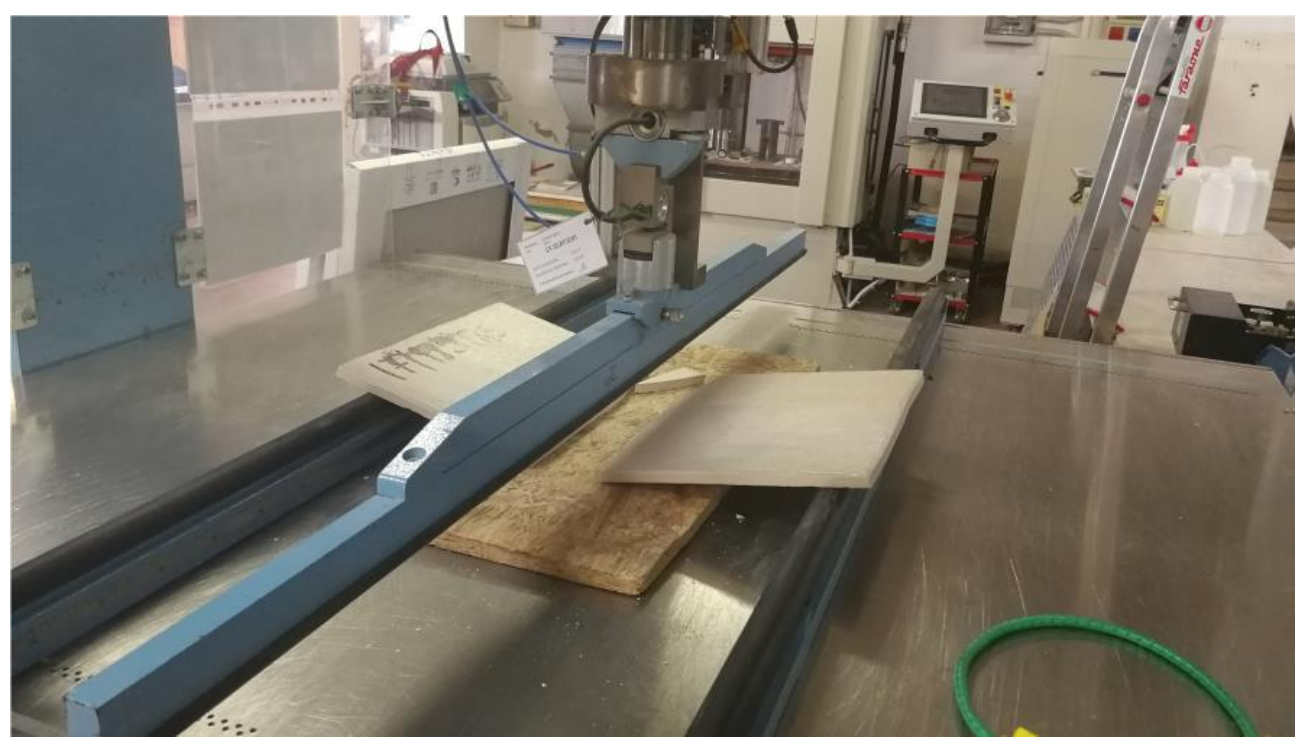

Figure 5 Transverse testing machine for mechanical measurements.

In particular, the tiles have the following requirements:

- Breaking strength requirements (UNI EN 13748-1 5.5): The breaking strength is deemed sufficient when the mean breaking strength of four specimens is more than or equal to $5 \mathrm{MPa}$, and when no individual result of the stress of failure is lower than $4 \mathrm{MPa}$.

- Breaking load requirements (UNI EN 13748-1 5.5): The breaking load is deemed sufficient when no individual result is found to be less than $2.5 \mathrm{kN}$ for tiles having a surface area less than or equal to $1100 \mathrm{~cm}^{2}$, or no individual result is less than $3 \mathrm{kN}$ for tiles with a surface area of more than $1100 \mathrm{~cm}^{2}$.

\section{Results and Discussions}

\subsection{Dimensional Compliance and Mechanical Performance}

The SL-ECO tiles were checked for the first dimensional compliance based on deviation from length and straightness. Figure 6 shows that the tiles were compliant to both the dimensional parameters i.e., length and straightness. The tiles had enough strength for both edges and the upper surface.
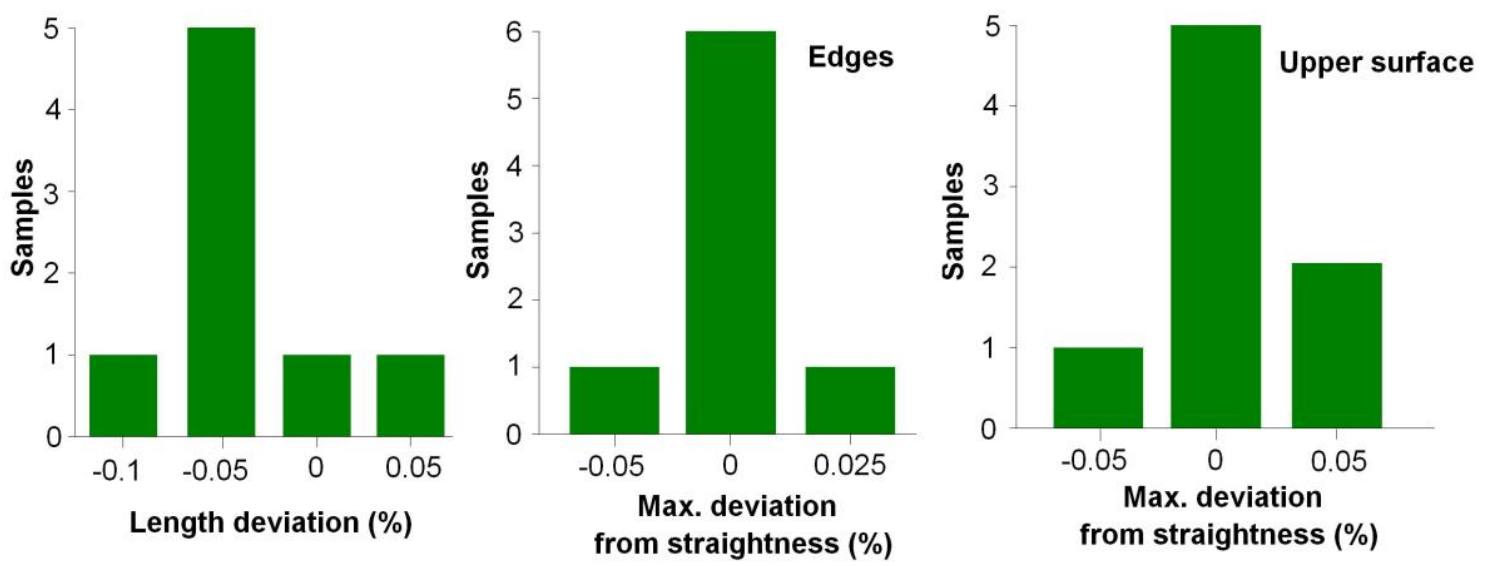

Figure 6 Dimensional compliance of single layer tiles. 
All the relevant mechanical results are presented in Table 3 as the average values followed by their relative standard deviations. The single layer tiles were compliant with the breaking strength but not with the breaking load, while the double layer tiles were compliant with both (Table 3). To therefore proceed with the industrial phase, the production company decided to increase the thickness of the SL tiles, which resulted in an improvement of their mechanical performance, suggesting that the industrialization and commercialization of these materials were feasible.

Table 3 Mechanical performance of the SL- and DL- ECO tiles.

\begin{tabular}{lll}
\hline Properties & Configuration & Values \\
\hline Breaking strength $(\mathrm{MPa})$ & Single layer & $8.48 \pm 0.43$ \\
& Double layer & $7.13 \pm 0.48$ \\
Breaking load $(\mathrm{kN})$ & Single layer & $1.22 \pm 0.05$ \\
& Double layer & $4.25 \pm 0.47$ \\
\hline
\end{tabular}

These products have been subsequently presented at the CERSAIE international fair and are available to the market for commercialization by the producer, as depicted in Figure 7.

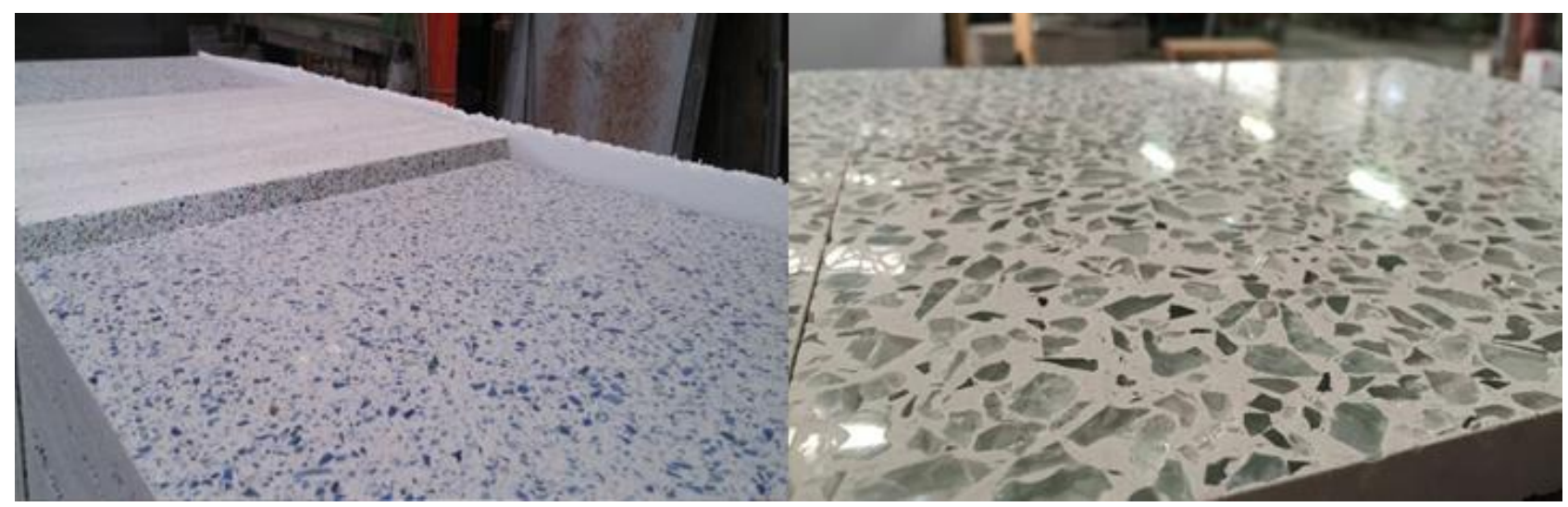

Figure 7 Industrialization phase at the Grandinetti company, using two different glasses.

\subsection{LCA Analysis}

The boundaries of the LCA system that are under study are reported in Figure 8, which concentrates on the raw materials used for the production of the Terrazzo tiles and the different production phases. In contrast, the impact caused due to waste disposal and water treatment is neglected, while the impacts of electricity, fuel, and transport are only considered when it is associated with the transfer of raw materials to the site of production. This was with the understanding that the study concentrates on the potential environmental substitution of raw materials, including recycled material, specifically glass wastes and CDW, in a specific production process. Table 4 reports the potential of global warming in terms of carbon footprint (in $\mathrm{kg} \mathrm{of} \mathrm{CO}_{2}$ 
equivalents per functional unit) measured during the different phases of the life cycle for each of the four analyzed tile configurations. The represented data show how the recovery phase of the raw materials has the highest impact on the total amount of $\mathrm{CO}_{2}$ produced in the life cycle of a Terrazzo tile.

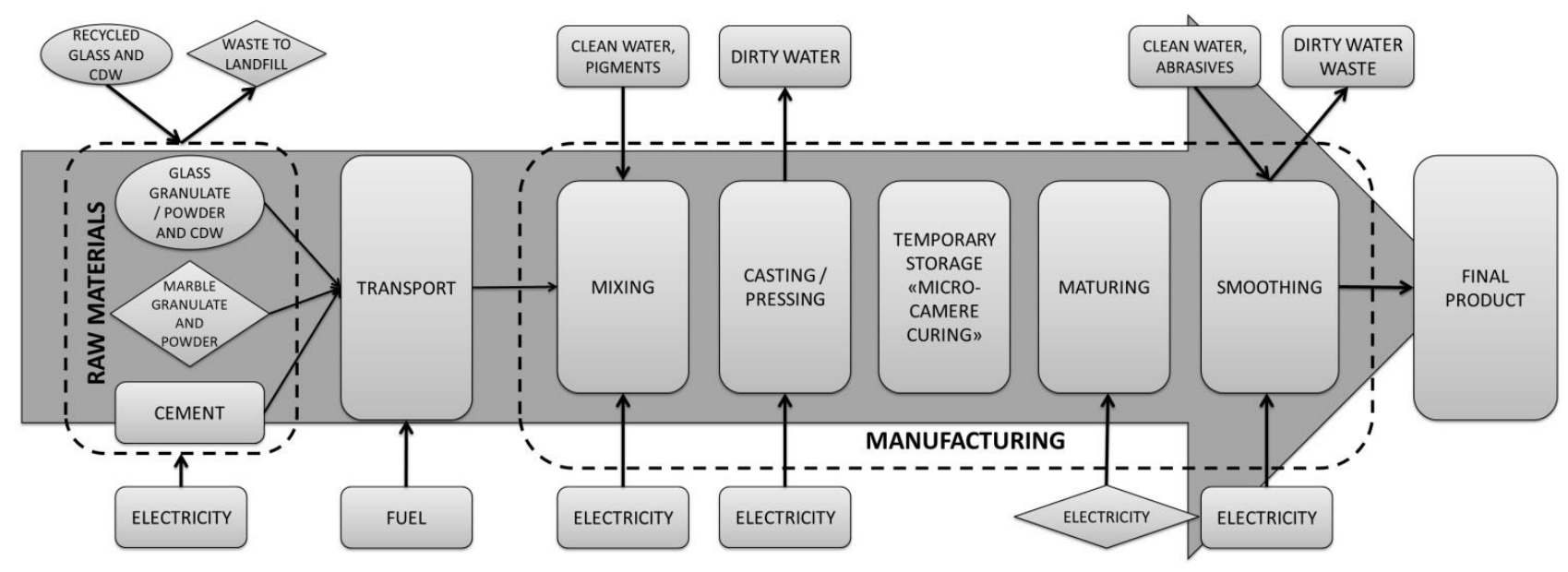

Figure 8 Boundaries of the LCA system are considered. Diamond boxes are processes exclusive to traditional tiles (TRAD) and rounded boxes are exclusive to ecological tiles (ECO).

Table 4 Carbon footprint impact ( $\mathrm{kg}$ of $\mathrm{CO}_{2 \text { eq }}$ per f.u.) calculated for each life phase of the four tile configurations were studied.

\begin{tabular}{lllll}
\hline & SL-TRA & SL-ECO & DL-TRA & DL-ECO \\
\hline Raw materials & 8.93 & 7.70 & 16.34 & 15.39 \\
Transport & 1.00 & 0.82 & 1.07 & 0.89 \\
Production & 1.69 & 1.26 & 2.21 & 1,85 \\
End-of-Life & 0.40 & 0.00 & 0.71 & 0.00 \\
Total & 12.02 & 9.77 & 20.33 & 18.12 \\
\hline
\end{tabular}

More details are provided in Table 5, which indicates that the main contribution is from the cement content alone, and it accounts for more than half of the total $\mathrm{CO}_{2}$ output. The second most impacting phase is the production, which only accounts for $10 \%$ of the total $\mathrm{CO}_{2}$ output. The transport and usage phases only account for around $5 \%$ of the total impact when considered together. In the ecological Terrazzo tiles, the reduction of $\mathrm{CO}_{2}$ associated with transport is mainly dependent on the proximity of the production sites with the recycling facilities available compared to the marble extraction quarries. It is important to note that in Italy, the glass recycling facilities are distributed at the regional level, while the marble quarries are located exclusively in a few geological sites (e.g., Northern Tuscany or the Alps area). In the production step, the only process, which contributes to the reduction of $\mathrm{CO}_{2}$ is maturing. This is because the maturing of the ecological Terrazzo is conducted using the patented process of exploiting the exothermic reaction that takes place during the cement setting, which avoids the need for additional heat required to reduce the setting time, to speed up the tile production, and to reduce the energy usage. Finally, the use of the recycled material in the ecological tile processing allows completely avoiding the 
landfill of end-of-life products and associated environmental impacts, as the ecological tiles can be fully reintegrated in the production cycle as CDW (end-of-life phase).

Table 5 Environmental indicators for the four case studies.

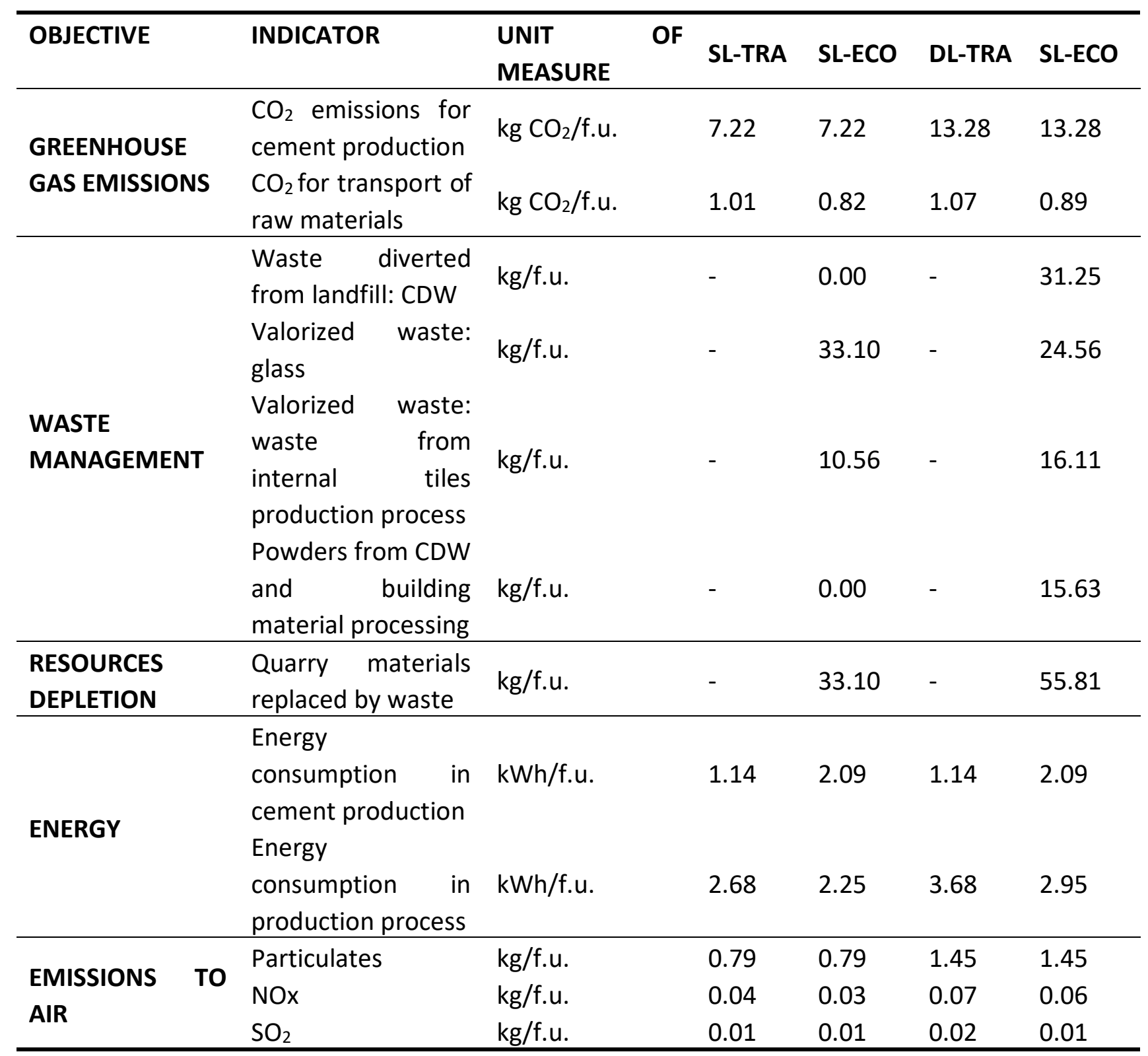

Preliminary scrutiny of the data from Table 5 reveals that as a whole, compared to the traditional Terrazzo tiles, the ecological Terrazzo tiles achieve significant benefits in terms of consumption of resources, owing to the complete substitution of marble and sand with the CDW and recycled glass (Waste management and Resources depletion objectives), reduction of consumed energy (avoiding the high amount of energy generally used in marble quarrying operations), and higher efficiency in the production processes with a particular reference to the maturing step (Energy objective). The emissions of $\mathrm{NO}_{x}$ and $\mathrm{SO}_{2}$ particulates are comparatively low and are associated exclusively with marble quarrying and cement production. In this regard, it is worth highlighting how the literature data on cement production and the marble quarrying 
activities confirm that most of the emissions are composed of $\mathrm{CO}_{2}$, while $\mathrm{NO}_{\mathrm{x}}$ and $\mathrm{SO}_{2}$ emissions are lower by orders of 2-3 magnitudes [41-43].

In contrast, the GWP impact of the double-layer tiles is higher than the single-layer tiles for both the traditional and ecological types, as reported in detail in Table 6 and Table 7. The increase in the GWP is largely attributed to the increase in materials required for the production of $1 \mathrm{~m}^{2}$ (i.e., 1 functional unit) of tiles, which is almost twice the thickness and the weight of the single layer. This factor also affects the transportation step and also the mixing, casting, and maturing of items in the production step. Again, the bill of $\mathrm{CO}_{2}$ associated with the usage step is almost twice as large in the traditional double-layered tiles compared to the traditional single-layered ones. The same considerations prescribed for the single-layered ecological tiles also apply for the doublelayered ones. 
Table 6 Input and output data for a functional unit $\left(\mathrm{m}^{2}\right)$ of SL-TRA tile and SL-ECO tile*.

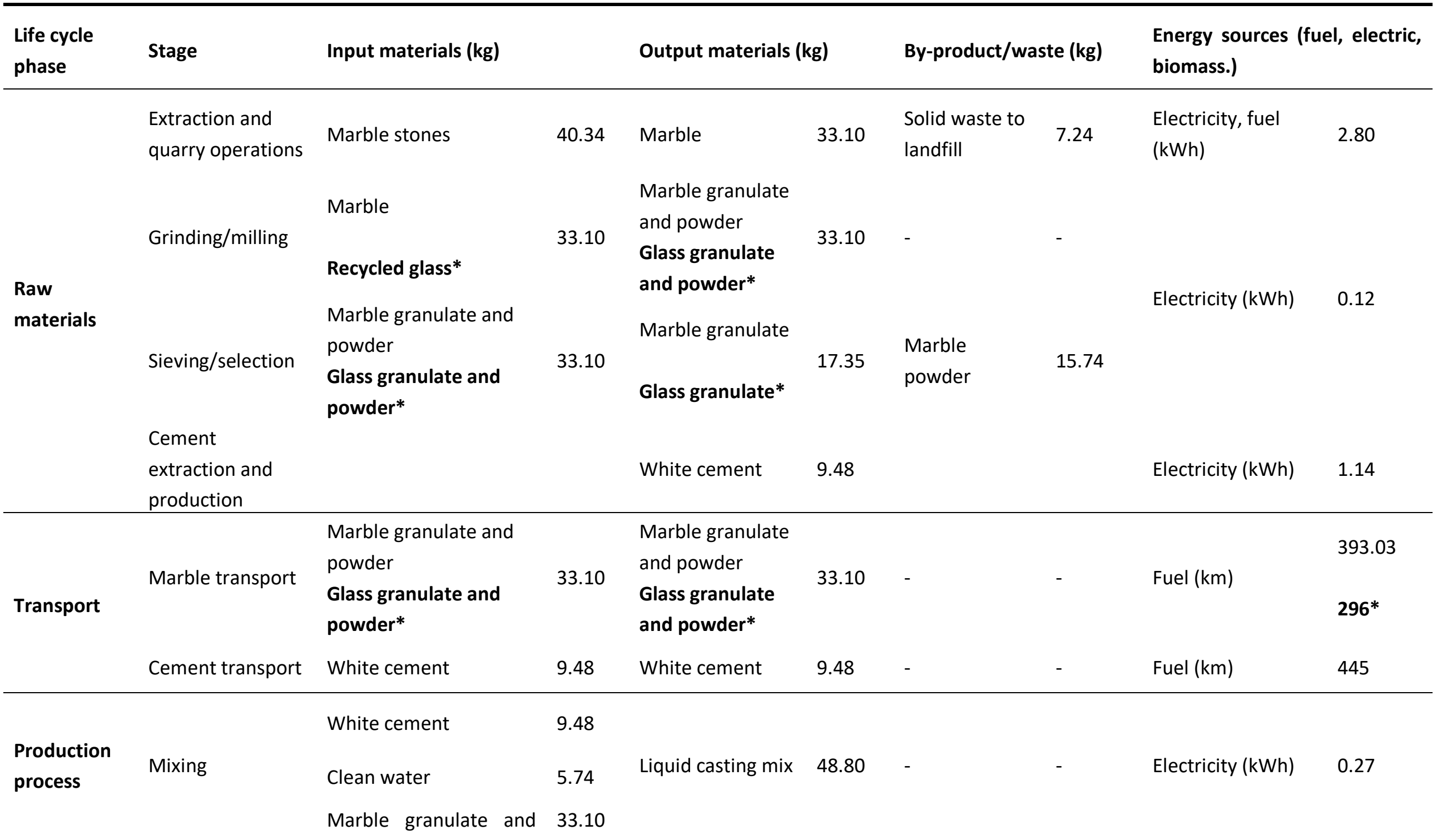




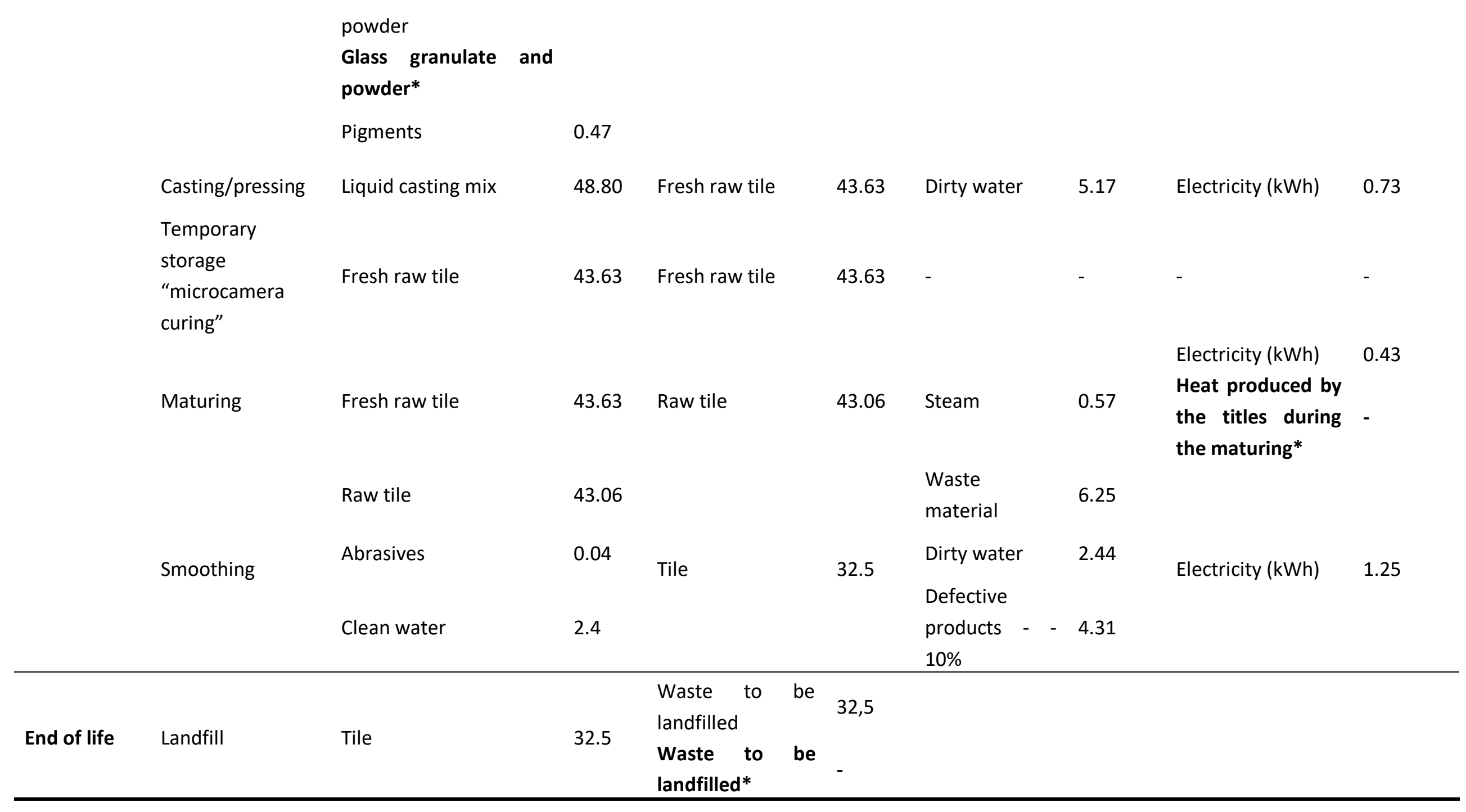


Table 7 Input and output data for a functional unit $\left(\mathrm{m}^{2}\right)$ of DL-TRA tile and DL-ECO tile*.

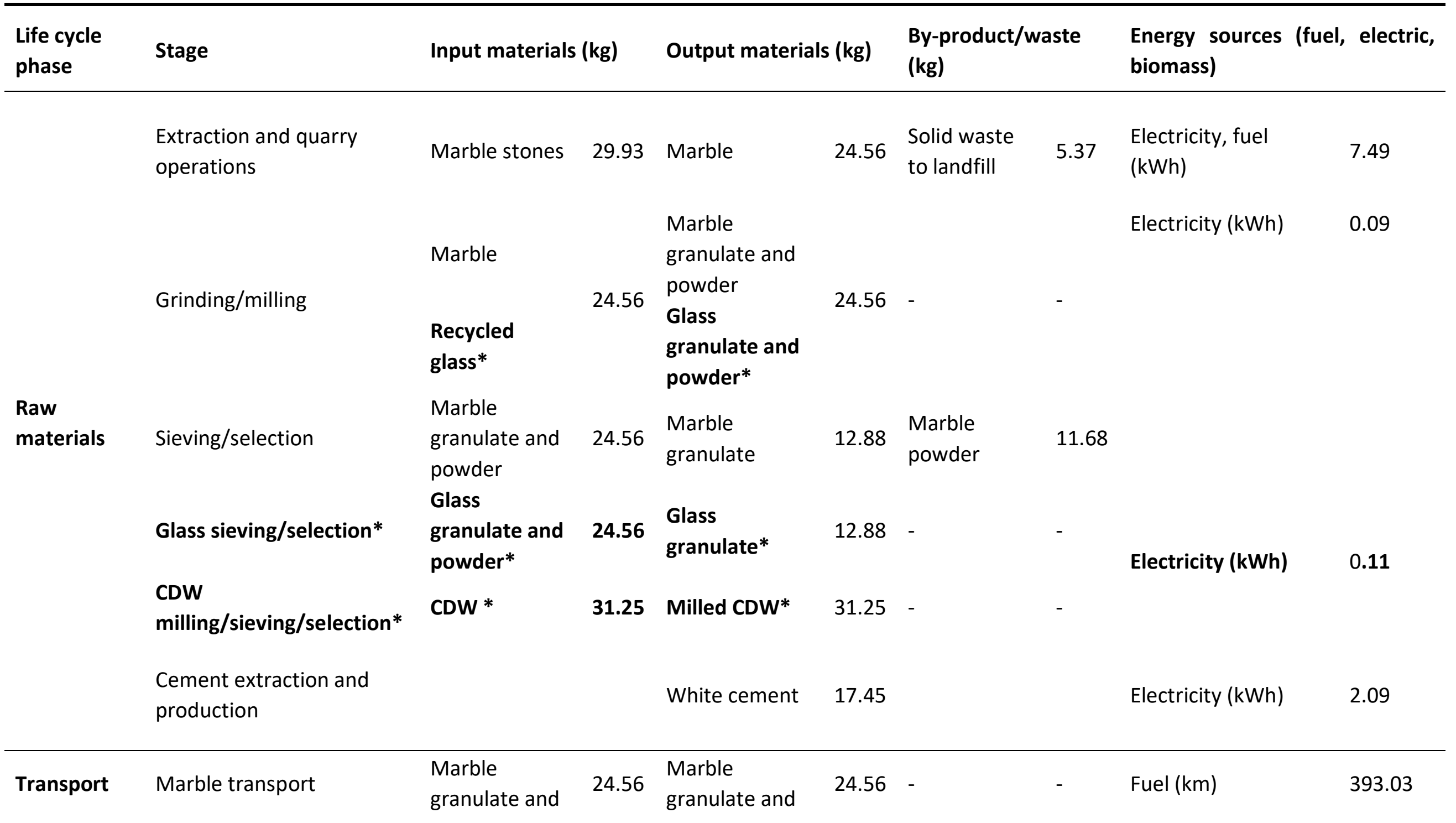




\begin{tabular}{|c|c|c|c|c|c|c|c|c|c|}
\hline & & powder & & powder & & & & & \\
\hline & Glass transport* & $\begin{array}{l}\text { Glass } \\
\text { granulate and } \\
\text { powder* }\end{array}$ & & $\begin{array}{l}\text { Glass granulate } \\
\text { and powder }\end{array}$ & & & & & \\
\hline & Sand transport & $\begin{array}{l}\text { Sand } \\
\text { Milled CDW* }\end{array}$ & 31.25 & $\begin{array}{l}\text { Sand } \\
\text { Milled CDW* }\end{array}$ & 31.25 & - & - & Fuel (km) & $\begin{array}{l}30 \\
6 *\end{array}$ \\
\hline & Cement transport & $\begin{array}{l}\text { White and } \\
\text { grey cement }\end{array}$ & 17.45 & $\begin{array}{l}\text { White and grey } \\
\text { cement }\end{array}$ & 17.45 & - & - & Fuel (km) & 445 \\
\hline \multirow{9}{*}{$\begin{array}{l}\text { Production } \\
\text { process }\end{array}$} & \multirow{8}{*}{ Mixing } & White cement & 7.04 & \multirow{8}{*}{$\begin{array}{l}\text { Liquid casting } \\
\text { mix }\end{array}$} & \multirow{8}{*}{83.43} & \multirow{8}{*}{-} & \multirow{8}{*}{-} & \multirow{8}{*}{ Electricity (kWh) } & \multirow{8}{*}{0.46} \\
\hline & & Clean water & 9.81 & & & & & & \\
\hline & & Marble & & & & & & & \\
\hline & & granulate and & & & & & & & \\
\hline & & $\begin{array}{l}\text { powder } \\
\text { Glass } \\
\text { granulate and } \\
\text { powder* }\end{array}$ & 24.56 & & & & & & \\
\hline & & $\begin{array}{l}\text { Sand } \\
\text { Milled CDW* }\end{array}$ & 31.25 & & & & & & \\
\hline & & Gray cement & 10.42 & & & & & & \\
\hline & & Pigments & 0.35 & & & & & & \\
\hline & Casting/pressing & $\begin{array}{l}\text { Liquid casting } \\
\text { mix }\end{array}$ & 83.43 & Fresh raw tile & 74.59 & Dirty water & 8.83 & Electricity (kWh) & 1.24 \\
\hline
\end{tabular}


Recent Progress in Materials 2021; 3(1), doi:10.21926/rpm.2101006

\begin{tabular}{|c|c|c|c|c|c|c|c|c|c|}
\hline & $\begin{array}{l}\text { Temporary storage } \\
\text { "microcamera curing" }\end{array}$ & Fresh raw tile & 74.59 & Fresh raw tile & 74.59 & - & - & - & - \\
\hline & Maturing & Fresh raw tile & 74.59 & Raw tile & 73.61 & Steam & 0.98 & $\begin{array}{l}\text { Electricity (kWh) } \\
\text { Heat produced by } \\
\text { the tiles during the } \\
\text { maturing* }\end{array}$ & $\begin{array}{l}0.73 \\
-\end{array}$ \\
\hline & & Raw tile & 73.61 & & & $\begin{array}{l}\text { Waste } \\
\text { material }\end{array}$ & 8.75 & & \\
\hline & Smoothing & Abrasives & 0.04 & Tile & 57.50 & & 2.44 & Electricity (kWh) & 1.25 \\
\hline & & Clean water & 2.40 & & 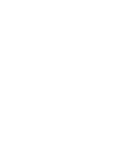 & $\begin{array}{l}\text { Defective } \\
\text { products - - } \\
10 \%\end{array}$ & 7.36 & & \\
\hline End of life & Landfill & Tile & 57.5 & $\begin{array}{l}\text { Waste to be } \\
\text { landfilled } \\
\text { Waste to be } \\
\text { landfilled* }\end{array}$ & $\begin{array}{r}57.5 \\
- \\
-\end{array}$ & & & & \\
\hline
\end{tabular}


Based on the results of the Impact Assessment of the Life Cycle and considering the complete life cycle, it shows how the production of the single and double-layered ecological tiles has an impact in terms of the GWP, which is significantly lower than the production of the traditional Terrazzo tiles. In particular, the production of an ecological single-layer (SL-ECO) Terrazzo tile shows better management of waste and natural resources. Owing to the complete substitution of traditional raw material with recycled glass; it is interesting to notice that, while this substitution accounts for $40 \%$ of the weight of the tile manufacturing materials, the gain in terms of GWP is just $14 \%$, as most of the $\mathrm{CO}_{2 \text { eq }}$ is obtained from cement production. Also, the reduction of energy consumption during the production process is equal to about $16 \%$, with particular reference to the maturing step that is performed using no additional energy but through a natural process. Overall, the savings achieved by the single-layer ecological (SL-ECO) Terrazzo production process in terms of $\mathrm{CO}_{2 \text { eq }}$ are considerable, as they account for $19 \%$. The greatest benefits are related to the use of recycled materials, in line with the EU policy on the circular economy in the industrial compartment. In particular, the reduction of energy consumption related to the maturing process amounts to about $20 \%$, while the savings in terms of $\mathrm{CO}_{2 \text { eq }}$ emissions is equal to $11 \%$.

\subsubsection{Interpretation}

The results of the LCA study revealed that the substitution of the recycled material and the implementation of innovative production techniques for the production of traditional Terrazzo tiles improved the sustainability of the product in terms of GWP. The study also revealed that the major contributor in the production of $\mathrm{CO}_{2}$ was cement, single-handedly accounting for $60 \%$ to $75 \%$ of the total $\mathrm{CO}_{2}$ output. In this view, to improve the efficiency in terms of the GWP of an ecological tile, major efforts should be addressed on the reduction of the cement fraction or even its substitution with new binding techniques.

How can this innovation contribute to the Terrazzo tiles market, and in which way does this improvement compare with the environmental impact of the traditional ceramic tiles? To answer this question, it would be useful to quantify the production and sales volume in the Terrazzo tile marketing sector. However, these parameters are very difficult to be accounted for due to the lack of national economic statistics, as this is considered to be a niche market compared to the ceramic tile market. There is no actual commercial classification regarding the Terrazzo tile firms present in Italy. The closest market macro-category that includes Terrazzo tiles is the Hard Flooring category (HFC), with Italy and Spain contributing for $41 \%$ and $34 \%$ to the whole European natural and agglomerated stones market, respectively [44]. In this data, the relevance of the production of Italian stone tiles in the European market is highlighted, but it hardly defines the share volume and the spread of the Italian Terrazzo tile production. According to a survey conducted by the authors on the tile retailers during the preliminary phases of the ecological tile production, there was a modest market demand for traditional cement-tiles: from a minimum of 5-10\% to a maximum of $20 \%$ of the entire tiles market, albeit it showed an increased demand in recent years. In Italy, the geographic areas with a higher demand for cement-tiles are in the metropolitan areas of Milan and Rome [45-46]. Additionally, cement-based tiles are required for restorations in nonurban/rural areas, where the floorings of old houses are often made up of cement-tiles and/or Terrazzo tiles. 
A comparison with ceramic tiles, although useful, could be misleading since the two products widely differ in terms of components and production processes having unique performances, market value, durability, and product lifespan. In particular, the thickness of the product proved to have a great impact on the LCA results because the Functional Unit (f.u.) used for the LCA calculations in the flooring material is the paving surface $\left(\mathrm{m}^{2}\right)$ and not the product volume $\left(\mathrm{m}^{3}\right)$; thus, the thicker the product is, a higher quantity of raw/second raw material is considered in the LCA analysis. This is also the main reason why, while accounting for about the same percentage of the recycled waste, and also adding the CDW, the DL-ECO $(2.3 \mathrm{~cm}$ thick) has a higher impact than an SL-ECO (1.3 cm thick) or a common ceramic tile (which is only about $0.3 \mathrm{~cm}$ thick). This evaluation completely disregards the greater waste content (in weight) of the double-layered ecological tiles. This is done in the understanding that all the waste produced would be reintroduced in the production system, a perspective that does not appear to be very realistic presently, but can be set as a future objective.

This work, aimed at evaluating the production of Terrazzo tiles as a greener choice compared to the traditional tiles, while at the same time demonstrating that these products result to be mechanically/physically performant. The DL-tiles production resulted in being more compliant than the SL-tiles to both the mechanical tests performed (i.e., breaking strength and breaking load). This can have important implications in terms of the re-utilization of waste materials. For instance, we need to consider that the DL-tiles also account for the high content of CDW materials, in addition to the glass waste. This provides a feasible upcycling application for the CDW, from the alternative to backfilling. Currently, landfill disposal should be avoided for the majority of wastes, also due to the possibility of leaching waste materials into water beds. More severe legal restrictions in all industrial countries must be implemented due to the growing hostility of populations, but more importantly, for the environmental costs of landfill disposals [47]. Furthermore, it is necessary for more hazardous waste components to search for new technologies and applications that can immobilize them in a cementitious matrix, but also in polymeric or glass and glass-ceramic matrices [48-50].

Recent studies deal with different techniques that enable us to meet these needs, including solidification within the concrete, leaching with acids and other solvents, sintering, and vitrification [51-52]. For example, vitrification is taken as the preferred treatment as it is supported by studies indicating it as the most promising waste management technique that produces a stable vitreous material, can provide chemical stability, immobilizes toxic elements (e.g., $\mathrm{Cd}, \mathrm{Ni}$, etc.) in the glass structure, and decomposes the dioxins [53]. Thus, it allows the conversion of waste into more stable and glassy products, with the possible additional modification of the starting composition having glass-forming additives or with other waste materials that could be more suitable to promote the vitrification process.

\subsection{Mineralogical and Chemical Characterization at The Waste Interface}

After the development of the product, further tests were carried out to investigate whether the fine waste glass fractions could be added to cement having different fillers to prospectively produce different types of Terrazzo tiles.

With this aim, in addition to the ECO-Terrazzo tile with waste glass denominated as Glass Tile, other two varieties (Marble and Quartz Tiles) were produced for comparison during this project. In 
different cases, the fine fraction consisted of high-grade marble powder (Marble Tile), marble powder and quartz sand (Quartz Tile), and glass waste powder (Glass Tile), respectively. The three tiles were analyzed by X-Ray Powder Diffraction (XRPD) and Scanning Electron Microprobe (SEM) to investigate the different features related to the distinctive interfaces (the contact surface between the waste glass granulate and matrix) and the stress on the feasibility for producing highgrade quality Terrazzo tiles incorporating different types of materials. For this purpose, the tiles samples $(15 \times 15 \times 5 \mathrm{~mm})$ were checked for the presence and morphology of the mineral phases with the help of a ZEISS Gemini SIGMA 300 FESEM (Field Emission SEM) working at an acceleration voltage of $15 \mathrm{keV}$ and with a maximum magnification of $1.2 \mathrm{~nm}$.

In Figure 9, the XRPD patterns of the three different tile samples are reported. The peaks related to the three main components (Calcite, Quartz, and Portland Cement) have been identified. As expected, the Calcite content is higher in the Marble tiles compared to that in the Quartz and Glass Tiles, whereas Quartz is the dominant phase in the Quartz tile. Portland Cement is present approximately with the same quantity in all tiles (which is equal to approximately $22( \pm 0.5) \%$ ) and of course, is the only crystalline component of the glass tiles.

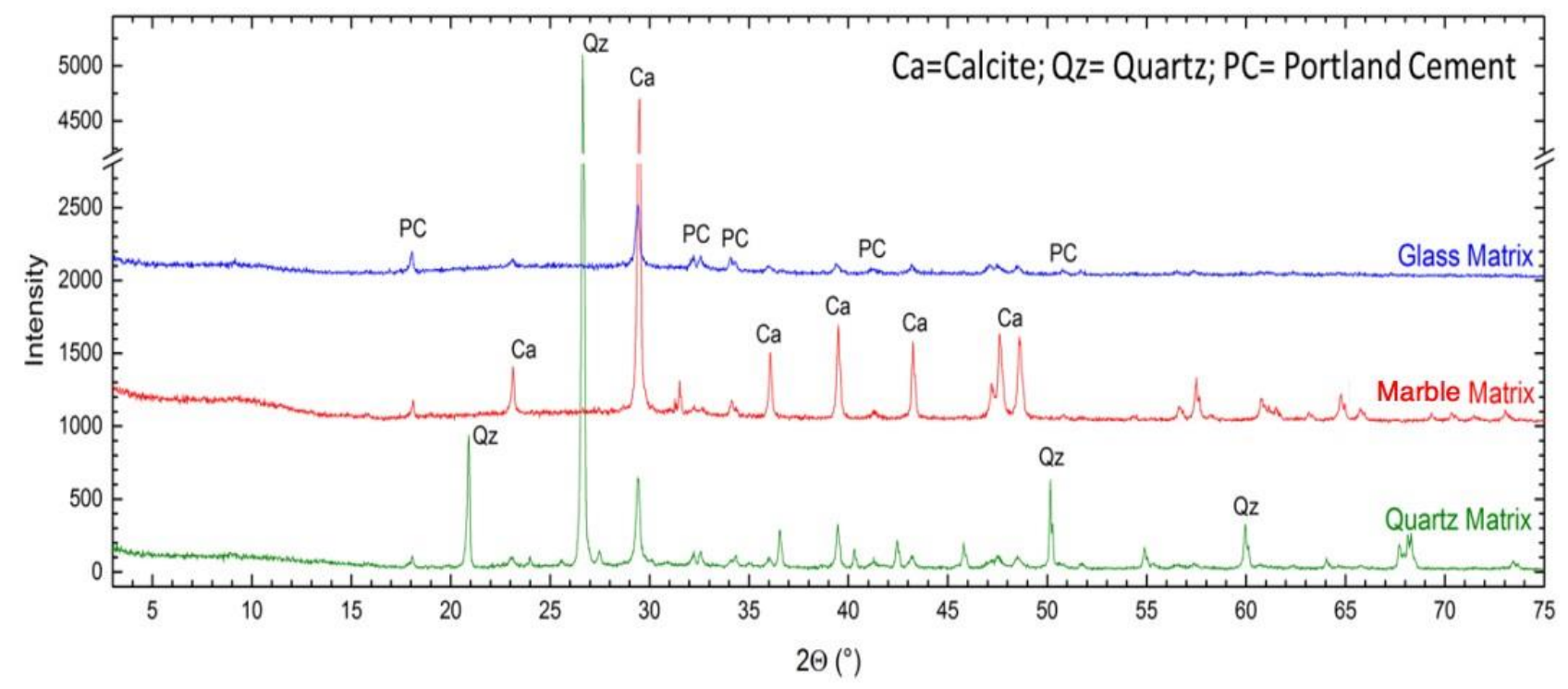

Figure 9 X-ray diffraction (XRD) pattern for the three different tile samples, Notes: $\mathrm{Ca}=$ Calcite, $\mathrm{PC}=$ Portland Cement, $\mathrm{Qz}=\mathrm{Quartz}$.

The XRD analysis allowed the presence of other newly formed crystalline phases in the tiles to be excluded, possibly induced by the use of different matrix compositions. The main concerns for the use of waste glass in the production of cement-based tiles are expansion and cracking, which might be induced by the formation of alteration products or by mechanical problems. The introduction of large glass aggregates can enhance the chances of deleterious cracking and the eventual failure of the surrounding matrix in the tiles. For example, as a consequence of rapid temperature change, differential expansion or shrinkage of the glass grains occurs compared to the matrix. For this reason, the applications for glass-bearing tiles are more suitable for internal usage. On the other hand, to prevent potential chemical corrosion of the glass aggregates in the concrete that may cause expansion, pozzolanic material is introduced and is applied (e.g., metakaolin) as a substitution for Portland cement [14 and references therein]. 
By studying the SEM images of the cementitious tiles consisting of three different fillers, which resulted in the formation of Marble, Quartz, or Glass Tiles, it was possible to analyze the interface between the waste glass grains and the respective matrix (Figure 10, left). While both the Marble and Quartz tiles present a well-defined boundary, the grain edges of the glass waste in the Glass Tile are slightly less defined. This is due to the chemical affinity between the glass grains and the glass matrix, which also formed continuity between the two components during the cutting procedure, which was used to prepare the sample for the SEM analysis. The use of glass for the two components (fine part and aggregate) appears to show a decrease in the possible mechanical stress at the interface.
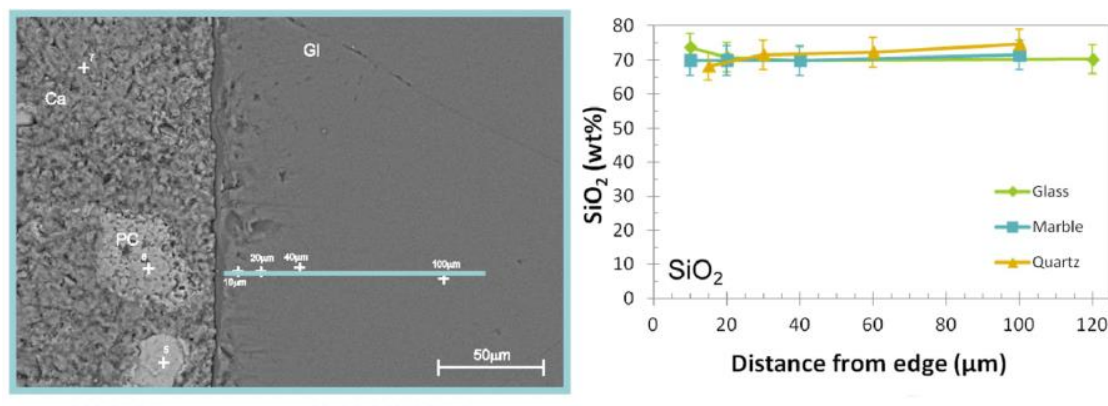

MARBLE

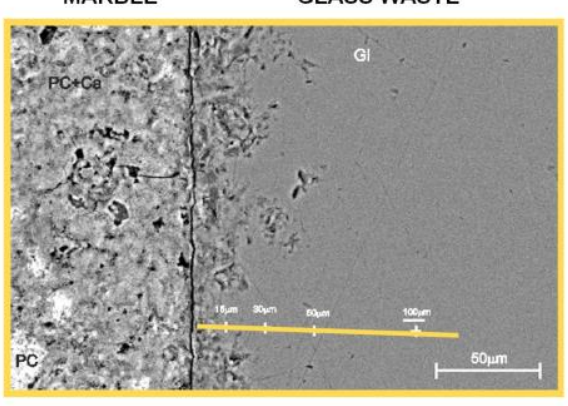

QUARTZ

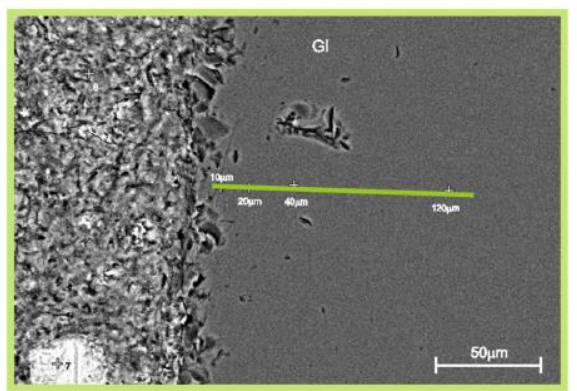

GLASS

GLASS WASTE
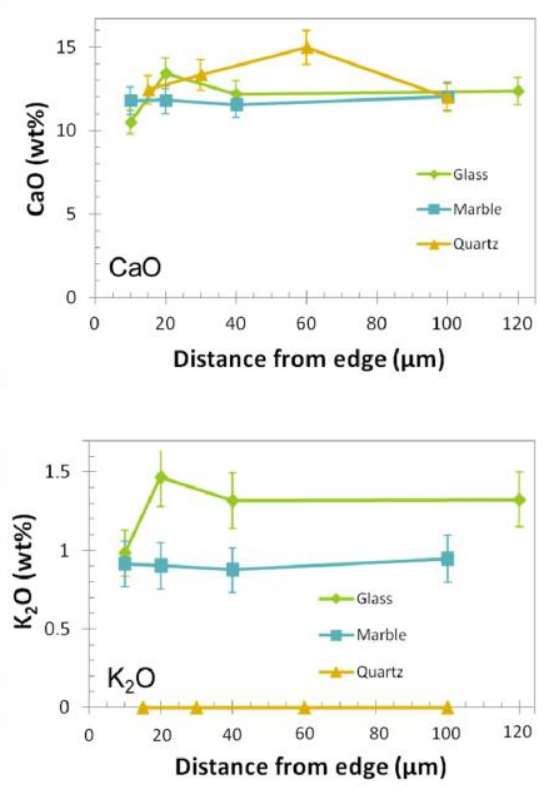
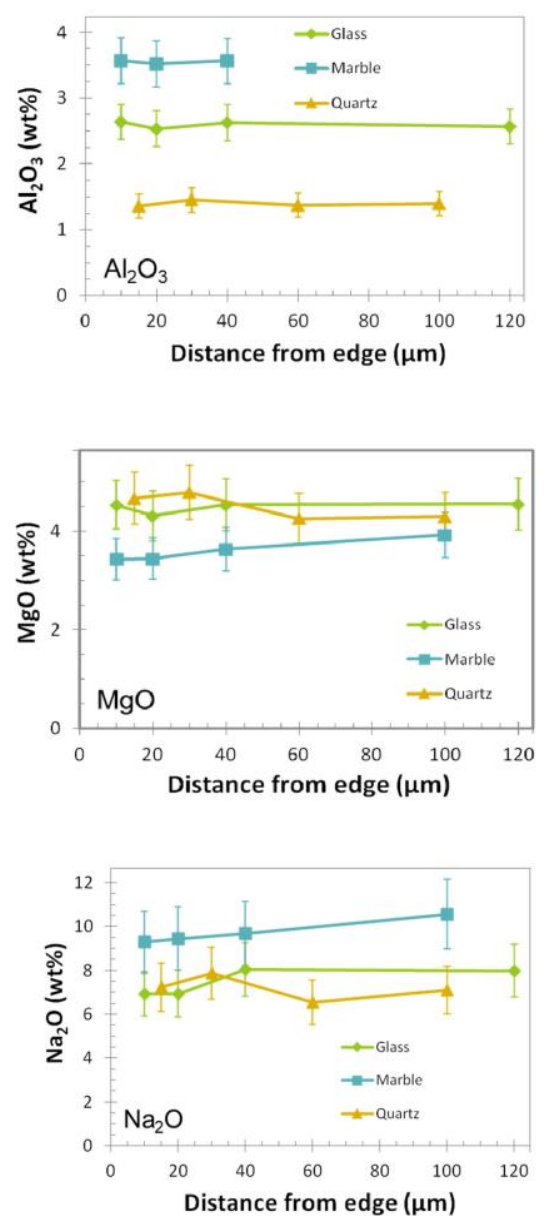

Figure 10 SEM images of aggregate- glass waste interface (left side): Notes: Ca=Calcite, PC = Portland Cement, GI =Waste Glass; compositional profiles (right side).

However, no discontinuities between the glass grains and the matrix were observed, which suggested a good adhesion among the components. Importantly, no cracks were observed, indicating that the glass waste could be successfully incorporated as both as fine and aggregate elements. The compositional trends of the major oxides for the three samples (Figure 10, right), except for the slightly different behavior of Potassium in the Quartz tile show that the values were comparable within the errors among the samples. This suggests that no substantial chemical variation was seen with the distance from the glass edge, indicating that there is no formation of alteration products at the glass/matrix interfaces in all three samples. 


\section{Conclusions}

The literature shows that the use of glass waste and construction and demolition waste (CDW) in concretes indicated several critical aspects, including a high heterogeneity and variable granulometry of the material in the case of the CDW. This result is found when introduced into a concrete matrix, resulting in the possibility of mechanical and structural weakening due to the waste penetrating the matrix.

Despite these risks, this study demonstrates that in a flooring product such as the Terrazzo tiles, satisfactory properties in terms of conformity and mechanical performance can be obtained. Along with these characteristics, the possibility of obtaining a high-grade precast product along with ample possibilities of market customization can offer a good possibility to incorporate high proportions of waste. This is of particular interest, while also bearing in mind that the disposal of rubble, as well as the manufacturing of Terrazzo tile products, can be carried out on a local basis, and therefore a much more accurate control on the waste supply takes place, while also providing benefits for the local economy.

The advantages in terms of the LCA are obvious as far as the reduced resource depletion, energy consumption, and the equivalent general carbon dioxide emissions are concerned. This is particularly significant in this specific case, also in terms of the micro-curing process of these tiles. Further improvements are expected to be added for this product when all the components of the Terrazzo tiles, including the wastes used, are recycled locally through the introduction of a virtuous industrial partnership. This would favor closed-loop manufacturing and would show a decrease in the requirement of transportation of secondary raw materials. If technically possible, an increase in the content of the waste and a reduction of the cement fraction produced or even its substitution with new binding techniques would further improve the environmental value of the product. This appears to be a particularly decisive objective since the Terrazzo tiles are longlife products having wide market appreciation, and this confers a particular value to a positive Life Cycle Assessment after waste introduction.

The industrialization of "eco"-tiles have immediately started after the test campaign results and are thus commercialized worldwide presently, testifying to a growing interest in greener materials for the construction sector that can fulfill the qualitative requirements of the current EU regulations.

\section{Acknowledgments}

The authors acknowledge the Grandinetti company for the Terrazzo tile production.

\section{Author Contributions}

P. Stabile and F. Radica jointly wrote the paper draft and carried out the chemical characterization and mechanical tests; L. Ranza carried out the LCA study; M.R. Carroll coordinated the laboratory experiments and facilities; C. Santulli revised the manuscript acting also as correspondent author; E. Paris supervised the materials production, revised the manuscript and coordinated the project. 


\section{Funding}

This work has been carried out in the frame of the LIFE14 ENV/IT/000801 ECO TILES project, which has received funding from the LIFE Programme of the European Union (https://www.ecotiles-lifeproject.eu/).

\section{Competing Interests}

The authors have declared that no competing interests exist.

\section{References}

1. European Commission. Waste - construction and demolition waste (CDW) [Internet]. Brussels: European Commission; 2016. [cited date 2020 January 20th]. Available from: http://www.ec.europa.eu/environment/waste/construction_demolition.htm.

2. European Commission. Studies - resource efficient use of mixed wastes [Internet]. Brussels: European Commission; 2016 [cited date 2020 January 20th]. Available from: http://www.ec.europa.eu/environment/waste/studies/mixed waste.htm.

3. Villoria Saez P, del Río Merino M, Porras Amores C, de San Antonio Gonzalez A. European legislation and implementation measures in the management of construction and demolition waste. Open Constr Build Technol J. 2011; 5: 156-161.

4. del Río Merino M, García Navarro J, Villoria Saez P. Legal aspects which implement good practice measures in the management of construction and demolition waste. Open Constr Build Technol J. 2011; 5: 124-130.

5. Ghaffar SH, Burman $M$, Braimah N. Pathways to circular construction: An integrated management of construction and demolition waste for resource recovery. J Clean Prod. 2020; 244: 118710.

6. Solís-Guzmán J, Marrero M, Montes-Delgado MV, Ramírez-de-Arellano A. A Spanish model for quantification and management of construction waste. Waste Manage. 2009; 29: 2542-2548.

7. Hodge $M$, Ochsendorf J, Fernández J. Quantifying potential profit from material recycling: A case study in brick manufacturing. J Clean Prod. 2010; 18: 1190-1199.

8. Sieffert $Y$, Huygen JM, Daudon D. Sustainable construction with repurposed materials in the context of a civil engineering-architecture collaboration. J Clean Prod. 2014; 67: 125-138.

9. Kirchherr J, Reike D, Hekkert M. Conceptualizing the circular economy: An analysis of 114 definitions. Resour Conserv Recycl. 2017; 127: 221-232.

10. Liikanen M, Havukainen J, Grönman K, Horttanainen M. Construction and demolition waste streams from the material recovery point of view: A case study of the South Karelia region, Finland. WIT Transactions on Ecology and the Environment - Waste Management and the Environment IX. Southampton: WIT Press; 2019.

11. European Commission (DG ENV). Service contract on management of construction and demolition waste - SR1 [Internet]. Brussels: European Commission Directorate-General for Environment; 2011 [cited date 2020 January 20th]. Available from: https://ec.europa.eu/environment/waste/pdf/2011 CDW Report.pdf. 
12. Vandecasteele C, Heynen J, Goumans H. Materials recycling in construction: A review of the last 2 decades illustrated by the WASCON conferences. Waste Biomass Valorization. 2013; 4: 695-701.

13. Pacheco-Torgal F, Ding Y. Handbook of recycled concrete and demolition waste. Sawston: Woodhead Publishing; 2013.

14. Shi C, Zheng K. A review on the use of waste glasses in the production of cement and concrete. Resour Conserv Recycl. 2007; 52: 234-247.

15. Al-Bayati HK, Tighe SL, Achebe J. Influence of recycled concrete aggregate on volumetric properties of hot mix asphalt. Resour Conserv Recycl. 2018; 130: 200-214.

16. Li N, Han R, Lu X. Bibliometric analysis of research trends on solid waste reuse and recycling during 1992-2016. Resour Conserv Recycl. 2018; 130: 109-117.

17. Verian KP, Ashraf W, Cao Y. Properties of recycled concrete aggregate and their influence in new concrete production. Resour Conserv Recycl. 2018; 133: 30-49.

18. Hoffmann C, Schubert S, Leemann A, Motavalli M. Recycled concrete and mixed rubble as aggregates: Influence of variations in composition on the concrete properties and their use as structural material. Constr Build Mater. 2012; 35: 701-709.

19. Fortova K, Pavlu T. The utilization of the finest fraction of recycled aggregate from CDW for concrete. IOP Conf Ser Earth Environ Sci. 2019; 290: 012013.

20. Whittaker MJ, Grigoriadis K, Soutsos M, Sha W, Klinge A, Paganoni S, et al. Novel construction and demolition waste (CDW) treatment and uses to maximize reuse and recycling. Adv Build Energy Res. 2019: 13; 1-17.

21. Ferriz-Papi JA, Thomas S. Recycled aggregates from construction and demolition waste in the production of concrete blocks. J Constr Build Mater. 2020; 2: 1-6.

22. Kim KH, Jeon SE, Kim JK, Yang S. An experimental study on thermal conductivity of concrete. Cem Concr Res. 2003; 33: 363-371.

23. Akçaözoğlu S, Akçaözoğlu K, Atiş CD. Thermal conductivity, compressive strength and ultrasonic wave velocity of cementitious composite containing waste PET lightweight aggregate (WPLA). Compos B Eng. 2013; 45: 721-726.

24. Ramírez FM, Muñoz FB, López EL, Polanco AV. Thermal evaluation of structural concretes for construction of biodigesters. Energy Build. 2013; 58: 310-318.

25. Bravo M, Brito JD, Evangelista L. Thermal performance of concrete with recycled aggregates from CDW plants. Appl Sci. 2017; 7: 740.

26. Meyer $\mathrm{C}$, Baxter $\mathrm{S}$, Jin W. Alkali-aggregate reaction in concrete with waste glass as aggregate. Proceedings of 4th Materials Engineering Conference: Materials for the New Millennium; 1996 November 10th - 14th; Washington, DC. Reston, VA: American Society of Civil Engineers; 1996.

27. Meyer C, Baxter S. Use of recycled glass and fly ash for precast concrete. Final report. New York: New York State Energy Research and Development Authority; 1998; Rep. NYSERDA 9818.

28. Dyer TD, Dhir RK. Chemical reactions of glass cullet used as cement component. J Mater Civ Eng. 2001; 13: 412-417.

29. Dhir R, Dyer T, Tang A, Cui Y. Towards maximising the value and sustainable use of glass. Concrete. 2004; 38: 38-40. 
30. Shi $\mathrm{C}, \mathrm{Wu} \mathrm{Y}$, Shao $\mathrm{Y}$, Riefler $\mathrm{C}$. Alkali-aggregate reaction of concrete containing ground glass powder. Proceedings of the 12th International Conference on AAR in Concrete; 2004 October 15 - 19; Beijing, China. Washington, DC: Sciences Engineering Medicine.

31. Shayan A, Xu A. Performance of glass powder as a pozzolanic material in concrete: A field trial on concrete slabs. Cem Concr Res. 2006; 36: 457-468.

32. Pacheco-Torgal F, Jalali S. Eco-efficient construction and building materials. London, UK: Springer Verlag; 2011.

33. Marie I, Quiasrawi $\mathrm{H}$. Closed-loop recycling of recycled concrete aggregates. J Clean Prod. 2012; 37:243-248.

34. Al-Zboon $\mathrm{K}$, Tahat $\mathrm{M}, \mathrm{Abu}$-Hamatteh $\mathrm{ZS}$, Al-Harahsheh MS. Recycling of stone cutting sludge in formulations of bricks and terrazzo tiles. Waste Manag Res. 2010; 28: 568-574.

35. Rodríguez C, Parra C, Casado G, Miñano I, Albaladejo F, Benito F, et al. The incorporation of construction and demolition wastes as recycled mixed aggregates in non-structural concrete precast pieces. J Clean Prod. 2016; 127: 152-161.

36. Soutsos MN, Tang K, Millard SG. Use of recycled demolition aggregate in precast products, phase II: Concrete paving blocks. Constr Build Mater. 2011; 25: 3131-3143.

37. Gabrielli F, Amato A, Balducci S, Galluzzi LM, Beolchini F. Disaster waste management in Italy: Analysis of recent case studies. Waste Manage. 2018; 71: 542-555.

38. Blengini GA, Garbarino E. Resources and waste management in Turin (Italy): The role of recycled aggregates in the sustainable supply mix. J Clean Prod. 2010; 18: 1021-1030.

39. Coelho A, De Brito J. Influence of construction and demolition waste management on the environmental impact of buildings. Waste Manage. 2012; 32: 532-541.

40. Borghi G, Pantini S, Rigamonti L. Life cycle assessment of non-hazardous construction and demolition waste (CDW) management in Lombardy Region (Italy). J Clean Prod. 2018; 184 : 815-825.

41. Habert G. 1-Environmental impact of Portland cement production. In Eco-Efficient Concrete. Sawston, UK: Woodhead Publishing; 2013. pp.3-25.

42. Stajanča M, Eštoková A. Environmental impacts of cement production. Теорія і практика будівництва. 2012; 737: 296-302.

43. Liguori V, Rizzo G, Traverso M. Marble quarrying: An energy and waste intensive activity in the production of building materials. WIT Trans Ecol Environ. 2008; 108: 197-207.

44. BRE. Green public procurement - Hard flooring coverings - Technical back ground report. Brussels: European Commission; 2011. [cited date 2021 January 20th] Available from: https://ec.europa.eu/environment/archives/ecolabel/product/pg hardfloor en.htm.

45. Ansaloni F, Radica F, Stabile P, Paris E. Ecological tiles from Urban Waste Glass and Construction \& Demolition Waste. Proceedings of 24th International Sustainable Development Research Society conference; 2018 June 13th-15th; Messina, Italy. Messina: The Organizing Committee of ISDRS 2018 Conference.

46. Ansaloni F, Paris E, Grandinetti V. The case of eco-tiles. Renew Matter. 2017; 17: 52-55.

47. Colombo P, Brusatin G, Bernardo E, Scarinci G. Inertization and reuse of waste materials by vitrification and fabrication of glass-based products. Curr Opin Solid State Mater Sci. 2003; 7: 225-239. 
48. Erol M, Küçükbayrak S, Ersoy-Mericboyu A. Comparison of the properties of glass, glassceramic and ceramic materials produced from coal fly ash. J Hazard Mater. 2008; 153: 418425.

49. Stabile $P$, Bello M, Petrelli M, Paris E, Carroll MR. Vitrification treatment of municipal solid waste bottom ash. Waste Manage. 2019; 95: 250-258.

50. Hossain N, Bhuiyan MA, Pramanik BK, Nizamuddin S, Griffin G. Waste materials for wastewater treatment and waste adsorbents for biofuel and cement supplement applications: A critical review. J Clean Prod. 2020; 255: 120261.

51. Haugsten KE, Gustavson B. Environmental properties of vitrified fly ash from hazardous and municipal waste incineration. Waste Manage. 2000; 20: 167-176.

52. Jung $\mathrm{CH}$, Matsuto $\mathrm{T}$, Tanaka $\mathrm{N}$. Behavior of metals in ash melting and gasification-melting of municipal solid waste (MSW). Waste Manage. 2005; 25: 301-310.

53. Kavouras P, Komninou P, Chrissafis K, Kaimakamis G, Kokkou S, Paraskevopoulos K, et al. Microstructural changes of processed vitrified solid waste products. J Eur Ceram Soc. 2003; 23: 1305-1311.

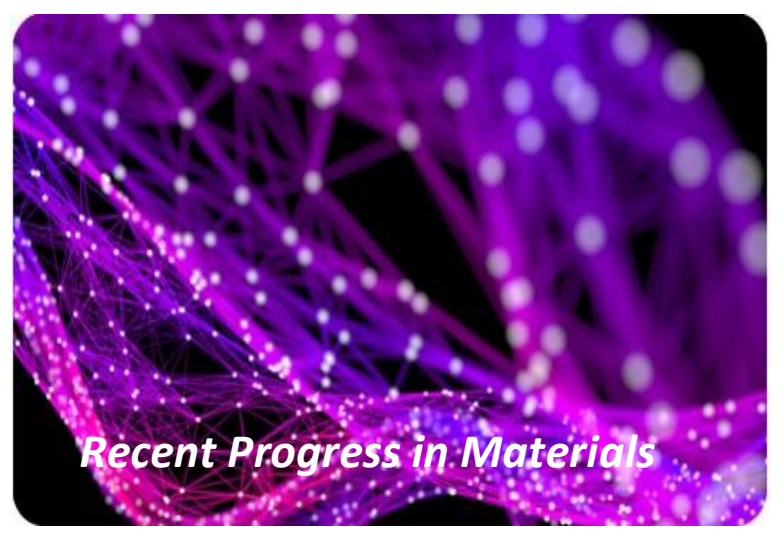

Enjoy Recent Progress in Materials by:

1. Submitting a manuscript

2. Joining in volunteer reviewer bank

3. Joining Editorial Board

4. Guest editing a special issue

For more details, please visit: http://www.lidsen.com/journals/rpm 